Arq. Bras. Med. Vet. Zootec., v.69, n.4, p.896-900, 2017

\title{
Avaliação biomecânica e dimensional do fio de sutura à base de quitosana
}

\author{
[Biomechanics and dimensional evaluation of the suture based on chitosan] \\ A.P. Alves ${ }^{1}$, M.J.C. Sá ${ }^{2}$, M.V.L. Fook ${ }^{2}$, G.C. Felipe ${ }^{1}$, F.V. Henrique ${ }^{1}$, \\ E.E. Albuquerque ${ }^{1}$, L.K.G. Medeiros ${ }^{2}$, P.R.S. Alexandre ${ }^{3}$ \\ ${ }^{1}$ Aluno de pós-graduação - Universidade Federal de Campina Grande - UFCG - Campus de Patos, PB
${ }^{2}$ Universidade Federal de Campina Grande - UFCG - Campus de Patos, PB
${ }^{3}$ Aluno de graduação - Universidade Federal de Campina Grande - UFCG - Campus de Patos, PB
}

RESUMO

A resistência à tração e o diâmetro são características de grande importância na avaliação da qualidade de fios de sutura, estando relacionados à capacidade destes de suportar o estresse promovido pelas forças atuantes em determinados tecidos. Desta forma, objetivou-se com este estudo avaliar as propriedades mecânica e dimensional de fios de sutura à base de quitosana, comparando-as com as preconizadas pela norma NBR 13904/2003. Tais propriedades foram avaliadas usando-se uma máquina de ensaio universal e um micrômetro digital. Os parâmetros mecânico e dimensional analisados foram a resistência quanto à tração, a deformação, bem como o diâmetro, respectivamente. O valor médio do diâmetro dos fios de quitosana apresentou variação e observou-se resistência à tração ligeiramente abaixo da norma preconizada, com rápida deformação. O fio de quitosana, na forma em que foi produzido, apresentou variabilidade dimensional e baixa resistência à tração, havendo a necessidade de melhorias no método de fabricação dele.

Palavras-chaves: biomecânica, polímero, quitina, tênsil

\begin{abstract}
Tensile strength and diameter are very important characteristics in assessing the quality of suture, being related to their ability to withstand the stress caused by forces acting in certain tissues. Thus, the aim of this study was to evaluate the mechanical and dimensional properties of chitosan-based suture, comparing them with those recommended by the NBR 13904/2003. These properties were evaluated by using a universal testing machine and a digital micrometer. The mechanical and dimensional parameters analyzed were resistance to traction, deformation and diameter, respectively. The average diameter of the chitosan showed variation and yarn tensile strength was observed slightly below the recommended standard, with rapid deformation. The chitosan yarn in the form in which it was produced, presented dimensional variability and low tensile strength, there is a need for improvements in the method of manufacturing the same.
\end{abstract}

Keywords: biomechanics, polymer, chitin, tensile

\section{INTRODUÇ̃̃̃O}

A quitosana é um biopolímero hidrofílico obtido da quitina, que é um dos polissacarídeos mais abundantes na natureza, extraído da casca de crustáceos ou, ainda, da parede celular de alguns fungos (Neto-Spin et al., 2008).

Recebido em 23 de julho de 2016 Aceito em 9 de setembro de 2016 E-mail: lane.p@hotmail.com
Os biomateriais à base de quitosana constituem uma classe que vem se destacando, apresentando propriedades usualmente aplicáveis em vários campos biomédicos. Assim, vários estudos têm sido realizados utilizando-se a quitosana na produção de diversos materiais especializados, tais como géis, pomadas, filmes, materiais para bandagens, soluções e fios de sutura, principalmente com modificações químicas $\mathrm{e}$ 
físicas, as quais têm promovido atividades biológicas para fins específicos (Neto-Spin et al., 2008; Aranaz et al., 2009).

Godeiro (2010) observou que o fio de quitosana utilizado nas suturas do peritônio de ratos apresentou pouca reação tecidual, com menor infiltrado inflamatório, mínima presença de fibroblasto e deposição de colágeno, quando comparado ao fio de náilon.

Um fio de sutura ideal deve apresentar características como: segurança no nó, resistência tênsil, fácil manuseio, mínima reação tecidual e adequada resistência durante a fase de cicatrização (Sandenberg et al. 2003). Assim, os estudos relacionados à produção de fios de sutura com tais propriedades estão cada vez mais frequentes na pesquisa voltada tanto à medicina humana quanto à veterinária.

A Norma NBR 13904, de maio de 2003, elaborada e editada pela Associação Brasileira de Normas Técnicas, regula as propriedades mecânicas e fixa os requisitos exigíveis para a liberação final do processo de fabricação de fios de sutura cirúrgica absorvíveis, não absorvíveis naturais e não absorvíveis sintéticos (Associação..., 2003).

Os ensaios biomecânicos têm uma grande importância na avaliação da qualidade do fio de sutura, uma vez que proporcionam informações relacionadas à capacidade do fio de suportar o estresse promovido pelas forças atuantes de determinados tecidos (Sandenberg et al., 2003). No ensaio mecânico de tração, o material é submetido à ação de duas forças opostas, aplicadas em pontos diferentes e sentidos contrários, provocando alongamento no sentido longitudinal e encurtamento no sentido transversal (Moraes et al., 2003). A resistência à tração é uma das características ideais que os fios de suturas precisam possuir, ela é a carga máxima que o fio de sutura é capaz de suportar até o ponto de ruptura (Castro et al., 2007; Campos et al., 2009).

Desta forma, objetivou-se com esse estudo avaliar as propriedades mecânica e dimensional de fios de sutura à base de quitosana, comparando-as com as preconizadas pela norma NBR 13904/2003.

\section{MATERIAL E MÉTODOS}

A produção do fio e os ensaios biomecânico e dimensional foram realizados no laboratório do Certbio, pertencente ao Departamento de Engenharia de Materiais da Universidade Federal de Campina Grande, Campus de Campina Grande, Paraíba, Brasil.

Os ensaios biomecânico e dimensional foram realizados por um único analista, em ambiente climatizado, com temperatura de $23,9^{\circ} \mathrm{C}$ e umidade relativa de $46 \%$.

Para a análise biomecânica, utilizou-se uma máquina de ensaio universal (modelo 3366, Instron) (Fig. 1) e o software Instron Bluehill, que controla a carga dada em Newton $(\mathrm{N})$, com velocidade de $120,00000 \mathrm{~mm} / \mathrm{min}$. Os parâmetros mecânicos analisados foram a resistência quanto à tração e a deformação do fio. As unidades utilizadas foram $\mathrm{N}$ (Newton) e milímetros (mm), respectivamente.

A análise do parâmetro dimensional foi realizada com micrômetro digital (modelo Coolant Proof, Série 293, Mitutoyo), com abertura de 0 a $25 \mathrm{~mm}$ e precisão de 0,01 . A dimensão analisada foi o diâmetro do fio, dado em milímetros (mm).

A metodologia utilizada para o estudo dos parâmetros foi a descrita na norma NBR 13904/2003 (Associação..., 2003).

Foram analisados 20 fios de suturas à base de quitosana. Os diâmetros foram avaliados no momento do ensaio de tração, para garantir que o fio estivesse completamente esticado, medindo-o em três pontos, aproximadamente, a $1 / 4,1 / 2$ e $3 / 4$ do comprimento total. Posteriormente, obteve-se a média das amostras e compararam-se os resultados com a norma - NBR 13904/2003 (Tab. 1). Depois, as extremidades do fio foram presas entre duas garras da máquina de ensaio universal, sendo o equipamento acionado até a ruptura do fio, registrando-se o instante do rompimento (Fig. 2).

Para a análise estatística, foi utilizado o programa computacional Bioestat 5.0, realizando-se a análise descritiva dos dados. 


\section{Alves et al.}

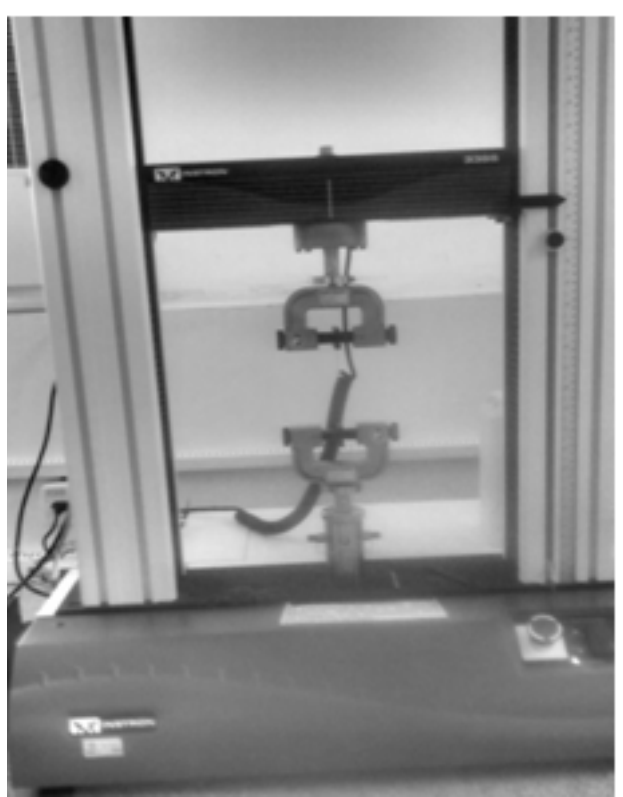

Figura 1. Máquina de ensaio universal.

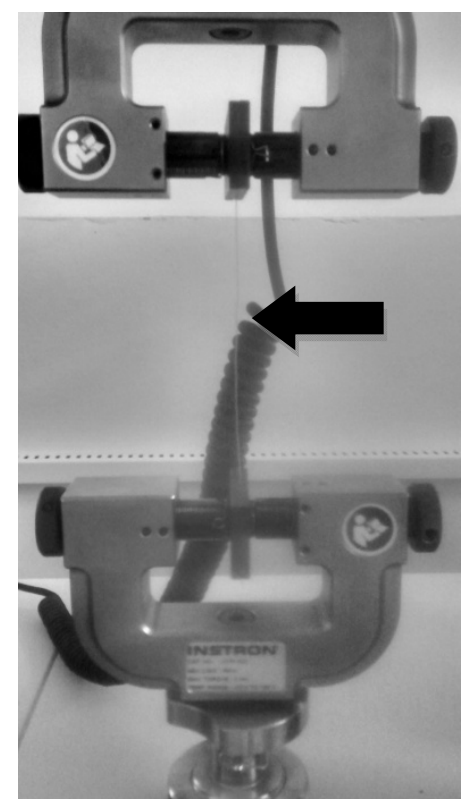

Figura 2. Ensaio mecânico do fio de quitosana no momento do teste (seta).

Tabela 1. Diâmetro e resistência à tração dos fios de suturas absorvíveis exigíveis pela NBR 13904/2003

\begin{tabular}{ccccc}
\hline & Número & \multicolumn{2}{c}{$\begin{array}{c}\text { Diâmetro } \\
(\mathrm{mm})\end{array}$} & $\begin{array}{c}\text { Resistência à tração } \\
(\mathrm{N})\end{array}$ \\
\hline Métrico & Cirúrgico & Mínimo & Máximo & Média \\
3 & $3-0$ & 0,300 & 0,339 & 12,26 \\
3,5 & $2-0$ & 0,350 & 0,399 & 19,62 \\
4 & 0 & 0,400 & 0,499 & 27,17 \\
\hline
\end{tabular}

Fonte: Adaptação, NBR 13904/2003.

\section{RESULTADOS E DISCUSSÃO}

O diâmetro dos fios de quitosana (Tab. 2) apresentou variabilidade, porém mostrou-se dentro da norma estabelecida pela NBR $13904 / 2003$ para os fios de sutura 3-0, que estabelece que nenhum dos diâmetros observados pode ser menor do que a média da faixa imediatamente anterior ou maior do que a média da faixa imediatamente posterior à faixa do fio analisado (Associação..., 2003) (Tab. 3).

Os resultados obtidos no ensaio biomecânico mostraram que os fios de quitosana estão em desacordo com a norma NBR 13904/2003, pois eles apresentaram resistência à tração menor do que exige a norma para fios de suturas com diâmetro 3-0, deformando-se rapidamente (Tab. 4). Acredita-se que a baixa resistência à tração esteja relacionada à variabilidade do diâmetro do fio, pois os locais de baixo diâmetro (menor área de secção) são zonas concentradoras de estresse, facilitando a ruptura dele. Um material com diâmetro regular distribui uniformemente toda força a ele exercida, conferindo-lhe maior resistência (Telles, 2009).

Tabela 2. Resultados dos diâmetros dos fios de quitosana após aferição dimensional

\begin{tabular}{cc}
\hline \multicolumn{2}{c}{ Diâmetro dos fios de quitosana $(\mathrm{mm})$} \\
\hline Diâmetro mínimo & 0,311 \\
Diâmetro máximo & 0,376 \\
Desvio-padrão & 0,032 \\
Média & 0,343 \\
Mediana & 0,343 \\
\hline
\end{tabular}

Fonte: Adaptação, NBR 13904/2003. 
Avaliação biomecânica...

Tabela 3. Valor médio dos diâmetros dos fios de suturas absorvíveis estabelecidos pela NBR 13904/2003

\begin{tabular}{ccccc}
\hline & Número & \multicolumn{3}{c}{ Diâmetro $(\mathrm{mm})$} \\
Métrico & Cirúrgico & Mínimo & Máximo & Média \\
2 & $4-0$ & 0,200 & 0,249 & 0,224 \\
3 & $3-0$ & 0,300 & 0,339 & 0,319 \\
3,5 & $2-0$ & 0,350 & 0,399 & 0,374 \\
4 & 0 & 0,400 & 0,499 & 0,449 \\
\hline
\end{tabular}

Fonte: Adaptação, NBR 13904/2003.

Tabela 4. Valor máximo da carga suportada pelo fio de quitosana durante o teste de resistência à tração, diâmetro médio, deformação e carga desejada, segundo a norma NBR 13904/2003 para fios 3-0

\begin{tabular}{cccccc}
\hline Fios & $\begin{array}{c}\text { Carga } \\
\text { máxima } \\
\text { obtida }(\mathrm{N})\end{array}$ & $\begin{array}{c}\text { Diâmetro } \\
\text { médio }(\mathrm{mm})\end{array}$ & $\begin{array}{c}\text { Deformação }(\mathrm{mm}) \\
\text { Quitosana }\end{array}$ & $\begin{array}{c}\text { Carga } \\
\text { desejada } \\
(\mathrm{N})\end{array}$ & $\begin{array}{c}\text { Percentual } \\
\text { adquirido }(\%)\end{array}$ \\
\hline Q,84027 & 0,3433 & 1,4 & 12,26 & $80,26 \%$ \\
\hline
\end{tabular}

Telles (2009), ao avaliar as propriedades mecânicas e dimensionais do fio de biopolímero da cana-de-açúcar, observou que este apresentou baixa resistência mecânica e grandes variações dimensionais, atribuindo a ausência de uniformidade no diâmetro do fio ao seu processo de fabricação artesanal, por meio de membranas circulares do biopolímero, não sendo ele submetido a técnicas de beneficiamento. Os fios de quitosana foram produzidos pela técnica de fiação úmida, que consiste em transformar fibras em fios resultantes da extrusão de polímeros mediante o uso de uma bomba infusora (Dentron e Daniels, 2002), não havendo nenhum processo de beneficiamento na fabricação dele, o que corrobora a afirmação feita por Telles (2009).

O diâmetro do fio de sutura tem uma grande importância na resposta inflamatória, pois a reação tecidual causada por ele é proporcional à sua espessura, ou seja, uma sutura feita com um fio de diâmetro calibroso apresenta uma resposta mais intensa no tecido do que aquela realizada com o mesmo tipo de fio, porém com diâmetro menor (Peterson et al., 2005). O fio de quitosana, por ter apresentado variação dimensional e pouca elasticidade, necessita de mais nós para dar sustentação à sutura, consequentemente há um maior acúmulo de material no local da ferida, provocando uma acentuada reação tecidual.

Durante o ensaio biomecânico, observou-se que os fios de quitosana usados no teste não apresentaram uma boa manipulação, pois eles estavam rígidos. Tais resultados corroboram a afirmação feita por Lapointe et al. (2016), os quais observaram que as suturas monofilamentares são mais rígidas e propensas para desatar, já as suturas multifilamentares exibem propriedades de manipulação mais favoráveis, com maior flexibilidade e elasticidade. A propriedade de elasticidade é importante, pois as suturas devem ser capazes de esticar para acomodar o edema da ferida e recuar para seu cumprimento original com a contração da ferida.

Recentemente, a reticulação vem sendo utilizada como uma das formas para modificação química estrutural da quitosana, a fim de aumentar sua estabilidade química e física. Para tanto, têm sido empregados diferentes agentes de ativação, como glicidol, epicloridrina, glutaraldeído, glioxal, formaldeído, trifosfato de sódio e genipina, formando estruturas complexas e, assim, conferindo maior resistência ao material (Mendes et al., 2011). Com isso, novos estudos podem ser feitos com agentes reticulantes, objetivando conferir mais resistência mecânica aos fios do polímero de quitosana.

\section{CONCLUSÃO}

O fio de quitosana, na forma em que foi produzido, apresentou variabilidade dimensional, baixa resistência à tração e pouca elasticidade, havendo a necessidade de melhorias no método de fabricação, além da realização de novos estudos acerca de métodos que confiram-lhe maior resistência 


\section{REFERÊNCIAS}

ARANAZ, I. et al. Functional characterization of chitin and chitosan. Curr. Chem. Biol., v.3, p.203-230, 2009.

ASSOCIAÇÃO BRASILEIRA DE NORMAS TÉCNICAS. NBR 13904. Fios para sutura cirúrgica. Rio de Janeiro, 2003. 15p.

CAMPOS, G.J.L.; LAUREANO FILHO. J.R.; CARVALHO, R.W.F. et al. Análise da resistência de tensão de três diferentes fios de sutura utilizados em cirurgia bucal. Rev. Bras. Cir. Cabeça Pescoço, v.38, p.15-18, 2009.

CASTRO, H.L. et al. Propriedades físicas dos fios de sutura usados na odontologia. Cienc. Odontol. Bras., v.10, p.85-90, 2007.

DENTRON, M.J.; DANIELS, P.N. Textile terms and definitions. Manchester: Textile Institute, 2002. 407p.

GODEIRO, J.R.S. Estudo comparativo da reação tecidual entre fios de nylon e quitosana em suturas no peritônio de ratos. 2010. 38f. Monografia (Graduação em Medicina Veterinária - Universidade Federal Rural do Semi-Árido.

LAPOINTE, S.; SIDÉRIS, L.; NOEL-CÉLESTIN, S. Effect of chemotherapy and heat on biomechanical properties of absorbable sutures. J. Surg. Res., p.5-65, 2016.
MORAES, J.R.E.; FÁVARO, A.F.; SHIMANO, A.C.; FERRARO. et al. Propriedades mecânicas de três fios de sutura no reparo do músculo flexor profundo do dedo de cães. Brazilian Journ al of Veterinary Research and Animal Science, v.40, p.443-451, 2003.

MENDES, A.A. et al. Aplicação de quitosana como suporte para a imobilização de enzimas de interesse industrial. Quím. Nova, v.34, p.831840, 2011.

NETO-SPIN, R. et al. Biomateriais à base de quitosana com aplicação médica e odontológica: revisão de literatura. Rev. Odontol. UNESP, v.37, p.155-161, 2008.

PETERSON, L.J. et al. Cirurgia oral $e$ maxilofacial contemporânea. Rio de Janeiro: Elsevier, 2005. 816p.

SANDENBERG, T. et al. Assessment of me chanical propertis and dimensions of suture threads utilized in orthopedic surgeries. Acta Ortop. Bras., v.11, p.88-94, 2003.

TELES, A.A.P. Avaliação das propriedades mecânicas e dimensões do fio do biopolímero da cana-de-açúcar e de fios de sutura utilizados em cirurgias ortopédicas. 2009. 30f. Monografia (Residência de Ortopedia e Traumatologia) Hospital Getúlio Vargas, Recife, PE. 